\section{Ebstein's Anomaly}

Edmar Atik

Instituto do Coração do Hospital das Clínicas da FMUSP, São Paulo, Brazil
Pediatric Cardiology has experienced changes in frameworks of clinical-surgery and catheterization percutaneous interventions, to the extent that there is a true revolution in current handling.

In this transformation, the prospects of this specialty have improved. Therefore, many anomalies are now considered even "cured" after surgical correction in a timely manner.

Concerning Ebstein's anomaly, its gravity is known as to the age of appearance, especially in the neonatal period, with a mortality of approximately $50 \%$ of cases following the natural history, and about $30 \%$ of patients operated in this age group.

In long-term outcome, although it is considered the cyanogenic anomaly whose natural evolution is the longest of all, often exceeding the third or fourth decade of life, phenomena acquired with volume overload and right ventricular dysfunction affect this trajectory to the point of increasing surgery risk and postoperative morbidity with the advent of arrhythmias that are difficult to control, and greater deterioration of ventricular function.

Hence, the technique devised by da Silva et $\mathrm{al}^{1}$ for the correction of this challenging heart disease, through the cone technique, as it is called, becomes a technical breakthrough of great magnitude and momentum in the overall handling of Ebstein's anomaly.

The cone technique has been under development since 1989 by da Silva et $\mathrm{al}^{1}$, and adds to other tricuspid valve plastic surgeries for correction of Ebstein's anomaly in a more favorable manner due to lower mortality (3.8\%) compared to Danielson's (5.8\%), Carpentier's (9\%), and 13 institutions of the European Congenital Heart Surgery (13.3\%) under various techniques ${ }^{2}$, delivering even better results, including in the long-term with respect to the need for reintervention, and good functionality of the tricuspid valve and right ventricle ${ }^{1}$.

About the technique itself, I will simply mention that the tricuspid valve is positioned in the true ring and longitudinal plication of the atrialized right ventricle maintains adequate

\section{Keywords}

Ebstein anomaly, heart defects, congenital, tricuspid valve/surgery.

\footnotetext{
Mailing Address: Edmar Atik •

Rua Dona Adma Jafet, 74 conj. 73, Bela Vista - 01308-050 - São Paulo, SP, Brazil E-mail: eatik@cardiol.br, conatik@incor.usp.br

Manuscript received October 14, 2011; revised manuscript received October 18, 2011; accepted October 18, 2011.
}

size and morphology of the right ventricle. There were no complications such as atrioventricular block, and more significant residual lesions of tricuspid regurgitation were found in seven (17.5\%) out of 40 patients analyzed in the long term, compared to $30 \%$ in Carpentier's technique ${ }^{1}$. Worthy of note is that the cone technique can be performed in all patients, regardless of valve anatomy, unlike Danielson's, in which it was possible to perform plastic surgery in only $27 \%$ of the 186 patients operated ${ }^{1}$.

Relevant aspects of superiority over other techniques refer to the larger increase in the right ventricular area, which is measures in $\mathrm{cm}^{2} / \mathrm{m}^{2}$, and the smaller right atrium area. Although valve replacement with biological prosthesis is a good operative tactic, the cone technique outweighs it in terms of evolution with a maturity of more than 10 years, when the prosthesis enters in a period of progressive deterioration ${ }^{3}$.

It is imperative to point out that, in addition to the favorable aspect of this new corrective technique, as well as other unprecedented techniques developed in our country for the correction of other abnormalities, a higher reproducibility is required for the benefit of patients with Ebstein's anomaly.

The difficulty of this cone technique lies in its nonreproducibility and implementation in other medical centers. Henceforth, it is believed that it can be performed more often, stimulated by the good results shown in sufficient periods of long-term evolution.

Moreover, there is another aspect that should be further emphasized: the technique could be performed on younger patients than it is currently performed (18.5 \pm 13.8 years), in order to be able to prevent adverse and unfavorable evolutionary aspects, such as marked right ventricular dilatation with consequent ventricular dysfunction, which becomes an element of progressive deterioration, even after proper plastic correction of the tricuspid valve, although there was no occurrence of these unfavorable elements that hindered further evolution, according to the authors ${ }^{1}$. In this context, even in the presence of these risk elements, the cone technique can be applied, according to Liu et $\mathrm{al}^{4}$ in 30 of these patients, of which in 20 of them Glenn's bidirectional procedure was also employed concurrently (1,5 ventricle repair) vis-à-vis marked dilatation and right ventricular dysfunction, in an average age of 60 months (ranging from 2 to 192 months). The results obtained by these authors ${ }^{4}$ were also satisfactory, with reappearance of moderate to severe tricuspid regurgitation in four (13.3\%) patients, with one death (3.3\%).

According to the results shown by da Silva et $\mathrm{al}^{1}$, the cone technique is preferable to other techniques of valve 
replacement for prosthesis ${ }^{3}$, and Danielson's $(1979)^{1}$ and Carpentier's (1988) ${ }^{1}$ techniques, especially that of Starnes et $\mathrm{l}^{5}$ performed in the neonatal period. Hence, the technique may become the operation of choice especially if it is done earlier to avoid the factors that jeopardize subsequent developments.

As already shown, Glenn's bidirectional operation is useful in combination with the cone plastic surgery in the presence of ventricular dysfunction, and cardiac transplantation is employed in rare extreme cases of ventricular dysfunction associated.

Despite the promising advent of this new technique, Ebstein's anomaly is still considered critical in the neonatal period for half of the patients, who present no clinical improvement of hypoxia and heart failure with the use of vasodilators like prostaglandin E1. During this period, the Starnes' technique ${ }^{5}$ (exclusion of the right ventricle due to interruption of blood flow from the tricuspid valve with slotted membrane, combined with the Blalock-Taussig anastomosis) applies to most patients, limiting the indication of valve repair to anatomically more favorable and feasible cases.

In this age group, however, the Blalock-Taussig operation still has the best outcome in patients with hypoxemia that is difficult to control. Thus, according to Shinkawa et $\mathrm{al}^{6}$, the longterm survival of nine neonates who underwent this technique was $88.9 \%$ and $76.2 \%$ after one and 10 years respectively, while in 11 neonates undergoing the Starnes' operation ${ }^{5}$, survival amounted to $63.6 \%$ and $47.7 \%$, respectively, 10 and 15 years after the operation. The evolution of four neonates undergoing valve repair was the worst according to these authors $^{6}$, since the survival of the neonates corresponded to $25 \%$ with 1.5 and 10 years postoperatively.

We congratulate the authors of the cone technique and expect it to be able to achieve sufficient reproducibility to the point of including the Ebstein's anomaly in the group of conditions that can even be considered "cured", provided there is no residual lesion and preservation of normal ventricular function.

\section{References}

1. da Silva JP, Silva LF, Moreira LFP, Lopes LM, Franki SM, Lianza AC, et al. A ténica do cone para correção da anomalia de Ebstein: Resultados imediatos e em longo prazo. Arq Bras Cardiol. 2011;97(3):199-208.

2. Sarris GE, Giannopoulos NM, Tsoutsinos AJ, Chatzis AK, Kirvassilis G, Brawn WJ, et al. / European Congenital Heart Surgeons Association. Results of surgery for Ebstein anomaly: a multicenter study from the European Congenital Heart Surgeons Association. J Thorac Cardiovasc Surg. 2006;132(1):50-7.

3. Kiziltan HT, Theodoro DA, Warnes CA, O'Leary PW, Anderson BJ, Danielson GK. Late results of bioprosthetic tricuspid valve replacement in Ebstein's anomaly. Ann Thorac Surg. 1998;66(5):1539-45.

4. Liu J, Qiu L, Zhu Z, Chen H, Hong H. Cone reconstruction of the tricuspid valve in Ebstein anomaly with or without one and a half ventricle repair. J Thorac Cardiovasc Surg. 2011;141(5):1178-83.

5. Starnes VA, Pitlick PT, Bernstein D, Griffin ML, Choy M, Shumway NE. Ebstein's anomaly appearing in the neonate. A new surgical approach. J Thorac Cardiovasc Surg. 1991;101(6):1082-7.

6. Shinkawa T, Palimenakos AC, Gomez-Fifer CA, Charpie JR, Hirsch JC, Devaney EJ, et al. Management and long-term outcome of neonatal Ebstein anomaly. J Thorac Cardiovasc Surg. 2010;139(2):354-8. 